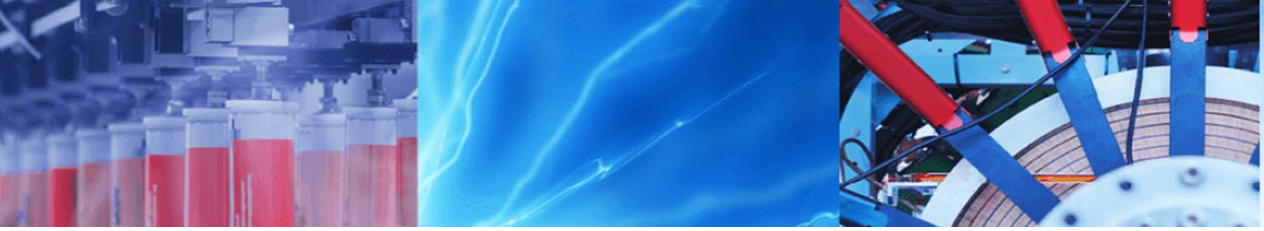

Research Article

\title{
Effect of nano filler concentration on leakage current and partial discharge properties of zepoxy nano composites
}

\author{
Taqi ur Rahman ${ }^{1}$. Salman Amin ${ }^{1} \cdot$ Hammad Shaukat ${ }^{1}$. Shaikh Saaqib Haroon ${ }^{1}$ - Intisar Ali Sajjad ${ }^{1}$. \\ Muhammad Awais ${ }^{1}$
}

(c) Springer Nature Switzerland AG 2019

\begin{abstract}
Electrical insulation materials play a key role in stable and uninterrupted operation of electrical power system. Researchers working in the field of electrical insulation have turned their focus to nano composite insulation materials for better performance and reliability. A typical nano composite insulation material is a combination of nano particles and base materials. Since last 25 years silicon rubber and epoxy are two widely used electrical insulation materials for outdoor and indoor applications respectively. To further enhance the electrical insulation performance of these materials addition of nano particles has proven to be of practical value. This study presents an investigation on zepoxy (a military grade epoxy) incorporated with three different nano particles at varying percentages. The main aim was to find the nature of relationship between leakage current (LC) and partial discharge (PD). In addition to that optimum composition which results in lowest values of PD and LC was also investigated for each of three nano composites. The results of this study help to understand the interdependence between LC and PD for indoor electrical insulation based on zepoxy. LC and PD play a vital role in condition assessment of any insulation material.
\end{abstract}

Keywords Partial discharge · Leakage current · Condition assessment of insulation

\section{Introduction}

Epoxy is an organic compound which consists of carbon chains attached with other elements like hydrogen, nitrogen and oxygen via a covalent band. Epoxy gets its name due to existence of epoxide functional group. The epoxide functional group is highly reactive and bonds with many materials to form rigid or flexible end products. Chemically speaking epoxy is an amorphous cross-linked polymer having good adhesive properties, able to bear harsh environmental conditions and survive under heavy loads. In 1930 epoxy was discovered by Dr. Sylvan and Dr. Pierre. Depending upon different applications epoxy is available in various forms.

Epoxy resin find widespread applications like circuit boards, bushings, insulators, instrument transformers and protection equipment [1]. Epoxy resins are developed for many outdoor and indoor insulation applications depending upon the voltage levels. Epoxy insulated transformers have replaced oil insulated transformers in many places. In comparison to oil insulated equipment epoxy insulated equipment has eliminated the insulation flashovers and contamination problems. Different kind of nano particles can be diffused in epoxy to form epoxy nano composite. Epoxy Nano composites are utilized in military applications, advanced aerospace, automobile applications, microelectronics and many more.

Since last two decades, involvement of nano particles in many composites have gained attention for enhancing properties of many polymers. The nano particles help to tailor the properties without changing the bulk chemistry of polymer. Nano dielectrics are the materials based on a

Taqi ur Rahman, rehmantaqi19@gmail.com | ${ }^{1}$ Electrical Engineering Department, University of Engineering and Technology Taxila, Taxila 47080, Pakistan.

SN Applied Sciences (2019) 1:1218 | https://doi.org/10.1007/s42452-019-1227-4 
polymer dielectric diffused with nano particles less than $100 \mathrm{~nm}$ in size. It has been proven that addition of nano particles enhances the electrical, mechanical and chemical properties of different polymers.

\subsection{Efforts done in previous studies}

The dielectric properties of epoxy with Al nano particles presented in [2] indicate an increase in dielectric constant with increasing \% age of $\mathrm{Al}$ nano particles. Dielectric spectroscopy of epoxy resin with $10 \mathrm{wt} \%$ of $\mathrm{Al}_{2} \mathrm{O}_{3}$ and $\mathrm{ZnO}$ nano and micro particles was investigated [3]. Results when compared with $\mathrm{TiO}_{2}$ nano particles reported in [4], showed that the addition of nano $\mathrm{TiO}_{2}$ and $\mathrm{ZnO}$ particles decreased the LC than base resin. Another study [5] reported that there is an interface created by the addition of nano particles which effect the dielectric strength of composites. This interface consist of three layers; transition, interfacial and loose layer [6]. A transition layer is a tightly bounded layer between polymer (organic) matrix and inorganic filler with the help of a coupling agent. A second layer is an interfacial layer which consist of polymer chains strongly attached to the transition layer and the surface of inorganic nano particles. A third layer is a loosely coupled and interacted region with the second layer. These three layers are mutually known as interaction zone [7]. In general it can be concluded that the introduction of nano particles basically creates a partially conductive region that permits uniform space charge distribution and significantly improves the breakdown properties of composite [8]. An increase in the permittivity of epoxy nano composites utilizing $\mathrm{TiO}_{2}, \mathrm{Al}_{2} \mathrm{O}_{3}$ and $\mathrm{ZnO}$ nano particles compared to base epoxy was reported in [9]. High permittivity results in lower resistivity and higher LC.

The PD resistance of LDPE filled MgO nano composite was discussed in [10] using a rod to plane electrode system. Significant improvement in PD resistance and minimum leakage was observed at lower filler loadings. It was observed that increasing filler concentration increases the permittivity which in turn increases ionization and LC. In another study [11] it was observed that PD resistance and LC of nano-micro composite (NMC) is lower than base epoxy. Tanaka et al. [12] reported that the addition of clay nano particles improved the PD resistance of raw epoxy. It was also reported that PD resistance of LDPE can be improved by $\mathrm{MgO}$ nano fillers up to $10 \mathrm{wt} \%$ Lee et al. [13] investigated the effect of silica micro and nano particles on the PD resistance of epoxy composite. The mixture of micro and nano composite gives better PD resistance than raw epoxy or single micro or nano particle. The reason of improvement in PD resistance is the compact assembly of nano fillers within the micro particles. Preetha et al. [14] investigated the PD properties of epoxy composites with alumina nano particles and found an increase in PD resistance even at very low concentration of nano particle. It was also observed $0.1 \mathrm{wt} \%$ alumina nano composite has less PD values in terms of pC. In study [15] the effect of micro and nano alumina particles on PD resistance of epoxy composites was reported. High concentration of micro particles improves PD resistance. Lower concentrations of nano particles increase PD resistance a little lower than micro particles. NMC of alumina improved the breakdown strength in addition to PD resistance of epoxy composites as reported in [16].

Chen et al. [17] investigated the dielectric properties of $\mathrm{TiO}_{2}$ and $\mathrm{TiO}_{2} @ \mathrm{SiO}_{2}$ epoxy nano composites. It was observed that $\mathrm{TiO}_{2} @ \mathrm{SiO}_{2}$ nano composite gives higher breakdown strength and lower $\mathrm{LC}$ than $\mathrm{TiO}_{2}$ nano composites. The dielectric properties of nano composites depends upon the dispersion of nano particles in base material [18]. Large interfacial regions are essential to improve the dielectric properties that's why coupling agents are used to control the interface size. Coupling agent improve the dispersion rate and transition temperature of nano composites [19]. If there is no control on interfaces then agglomeration of nano particles takes place which decreases the dielectric properties [20]. Effect of boron nitride nano core shell fibers (BNNF) in epoxy and related change in dielectric properties was investigated in $[21,22]$. It was observed that electrical conductivity and permittivity of nano composites increases with the increase in frequency. The dielectric properties of $\mathrm{TiO}_{2} @ \mathrm{SiO}_{2}$ nano composites were investigated in [23]. LC and volume resistivity of prepared epoxy nano composites decreases with the increase in filler concentration. It was observed that minimum value of $\mathrm{LC}$ occurs at $0.8 \%$ filler loading of $\mathrm{TiO}_{2} @ \mathrm{SiO}_{2}$ based nano composites.

PD and LC can be related to monitor aging process of insulation. In aging process there are two periods one is the early aging period and other is the late aging period [24]. In early aging period LC is small due to which PD occurs rarely. In this period the LC has only capacitive component. But in late aging period resistive component of LC increases that causes frequent PD. It was reported that deposited pollutants on insulator surface increase the PD activity and LC of insulation. It was observed that hydrophobicity loss, LC and PD are directly related in virgin as well as aged samples [25]. In electrical insulation field different dielectric properties like dielectric strength, resistivity and LC can be correlated. It was observed from literature that PD and LC values are effected by changing the configuration and testing conditions of nano composites. To understand the effective change in these values PD and LC can be correlated [26]. PD may exist in the region of strong electric field that ionizes the air and make it conductive. If contamination on the surface of insulator 
is prominent then it can provide an extra path for LC to flow. After applying the voltages across these surfaces a discharge will occur. PD arcs are more dominant in ionized region and these regions also have higher values of $\mathrm{LC}$ [27]. Different nano fillers like $\mathrm{TiO}_{2}, \mathrm{SiO}_{2}$ and $\mathrm{TiO}_{2} @ \mathrm{SiO}_{2}$ were selected. It was because of the fact that these three nano particles have been most widely investigated by many researchers in recent years. $\mathrm{SiO}_{2}$ nano particles are insulating particles while $\mathrm{TiO}_{2}$ are a little bit conductive in nature. Encapsulation of $\mathrm{TiO}_{2}$ nano particles in $\mathrm{SiO}_{2}$ outer nano layer provides a novel nano particle composition that has combined properties of $\mathrm{TiO}_{2}$ and $\mathrm{SiO}_{2}$.

\subsection{Novelty of research}

To monitor the health of insulator PD and LC are significant gears. It is clear from literature that during the aging of insulator both PD and LC are affected. Based upon the observation from literature this research was focused on finding the interdependence of PD and LC. The novelty of this study is to investigate the effect of nano filler concentration on LC and PD. In addition to that it compares LC and PD interdependence for three nano composites at different percentages of selected filler loadings.

\subsection{Characteristics of $\mathrm{SiO}_{2}$}

Silicon dioxide molecule consist of three-dimensional network or tetrahedral cells in which every silicon atom is attached with four oxygen atoms. Silicon dioxide is naturally formed in earth crust. It is also known as silica. Silica is stable up to $1600{ }^{\circ} \mathrm{C}$ which makes it suitable for different kinds of material processing. Many materials can diffuse in Silica due to which it has inherent property of stronger bonding with many materials resulting in strong dielectric materials. Due to greater dielectric strength and extensive band gap silica nano particles have outstanding insulating properties, compatibility and stability. Nano particles of silica when diffused in different polymer basis result in very strong polymer nano composite. Silica nano particles are mainly utilized in the field of energy storage, nano dielectrics, random access memories and transistors. The addition of silica nano particles improves the thermo mechanical and optical properties of many base polymers [28].

\subsection{Characteristics of $\mathrm{TiO}_{2}$}

$\mathrm{TiO}_{2}$ is a natural oxide which does not react with strong acids and reducing agents, but they can easily react with metals like $\mathrm{Li}, \mathrm{Na}, \mathrm{Mg}$ and $\mathrm{Ca}$. Titanium dioxides are used in paints, ceramic glazes, blocking of UV light, plastics, photo catalysts and electronic data storages. Titanium dioxide are also known as titania particles. These particles have higher permittivity and less dielectric strength as compared to silica nano particles. Due to this titania particles can be utilized in energy storage applications like super-capacitors and for making other kinds of polarizable dielectrics.

\subsection{Characteristics of $\mathrm{TiO}_{2} @ \mathrm{SiO}_{2}$}

$\mathrm{TiO}_{2} @ \mathrm{SiO}_{2}$ are highly polarizable nano particles in which $\mathrm{TiO}_{2}$ particles are encapsulated inside the $\mathrm{SiO}_{2}$ outer layer. In this case both the $\mathrm{TiO}_{2}$ particles and $\mathrm{SiO}_{2}$ layer are of nano meter dimensions. Encapsulating the $\mathrm{TiO}_{2}$ inside $\mathrm{SiO}_{2}$ layer at nano level results in a combination nano particle which has improved electrical and mechanical properties. This material is a fine white powder composed of titanium oxide particles ranging from 10 to $30 \mathrm{~nm}$ in diameter and coated with an outer layer of about $10-20 \mathrm{~nm}$ of $\mathrm{SiO}_{2}$. In this study $\mathrm{TiO}_{2}$, Rutile, 99.5\%, 20-30 nm, Coated with $10-20 \mathrm{~nm} \mathrm{SiO}{ }_{2}$ layer having density of $4.23 \mathrm{~g} / \mathrm{cm} 3$ was used. Some of the physical properties and electrical properties of $\mathrm{SiO}_{2}, \mathrm{TiO}_{2}$ and $\mathrm{TiO}_{2} @ \mathrm{SiO}_{2}$ are specified in Table 1.

\section{Design of experiment}

\subsection{Materials}

In this research zepoxy 300 was utilized as a base polymer matrix. Inorganic nano particles of $\mathrm{SiO}_{2}(30 \mathrm{~nm}), \mathrm{TiO}_{2}$ $(25 \mathrm{~nm})$ and $\mathrm{TiO}_{2} @ \mathrm{SiO}_{2}(40 \mathrm{~nm})$ were utilized to make different formulations. For every percentage of nano composite material formulated, five samples were made. Out of these five samples any samples having any kind of void or imperfection was discarded. Finally three defect free samples of each percentage were used for characterization of all parameters. Average of the three values is presented in all graphs. A total of 54 samples of 18 different formulations (3 samples of each formulation) were characterized. All zepoxy filled nano composites were tested on $100 \mathrm{kV}$ testing equipment. Error in tested values may be up to $1 \%$.

Table $1[17,23]$ Properties of $\mathrm{SiO}_{2}, \mathrm{TiO}_{2}$ and $\mathrm{TiO}_{2} @ \mathrm{SiO}_{2}$

\begin{tabular}{llll}
\hline & $\mathrm{Raw} \mathrm{SiO}_{2}$ & $\mathrm{Raw} \mathrm{TiO}$ & $\mathrm{TiO}_{2} @ \mathrm{SiO}_{2}$ \\
\hline Volume resistivity $(\Omega-\mathrm{cm})$ & $6 \times 10^{12}$ & $5.65 \times 10^{8}$ & $4.03 \times 10^{9}$ \\
Melting point $\left({ }^{\circ} \mathrm{C}\right)$ & 1600 & 1873 & 1840 \\
Permittivity $\varepsilon_{\mathrm{r}} @ 1 \mathrm{k} \mathrm{Hz}$ & 3.9 & 126.2 & 29.6 \\
Permittivity $\varepsilon_{\mathrm{r}} @ 10 \mathrm{k} \mathrm{Hz}$ & 2.8 & 67.2 & 19 \\
Permittivity $\varepsilon_{\mathrm{r}} @ 1 \mathrm{M} \mathrm{Hz}$ & 1.7 & 26.5 & 13.9 \\
\hline
\end{tabular}




\subsection{Preparation of nano composite}

Nano particles utilized are inorganic in nature therefore organic solvent acetone was utilized so that it cannot react with these particles to make a homogenous dispersion. First of all, each of nano particles were heated before use to ensure the removal of any trapped moisture. Then a weighed quantity of each nano particle was put in acetone and mixed mechanically for 20 min and ultrasonically for $30 \mathrm{~min}$. After that a weighed quantity of zepoxy resin was added into nano particles solution and magnetically stirred for $25 \mathrm{~min}$ along with heating. This mixture was then ultrasonicated for another $30 \mathrm{~min}$ at $55^{\circ} \mathrm{C}$. The resultant mixture was finally added with curing agent and put into molds for $24 \mathrm{~h}$ at room temperature to cure the nano composite. The formulations of nano composites prepared is listed in Table 2.

Some samples of bear zepoxy without any nano particles were prepared to compare their properties with the nano composites. The formulated nano composites were characterized using different electrical parameters like dielectric strength, permittivity, and resistivity, LC and PD.

\subsection{PD and LC measurements setup}

PD and LC are two significant parameters to monitor the health of an insulation. PD is a localized breakdown which usually occur inside the bulk of material due to air voids or on the surface due to partial wetness. LC is the creeping current which has three components, one flowing inside the bulk of material; second flowing through the boundary between material surface and air and third one through air. Measurement setups of PD and LC are shown in Fig. 1 . Figure 1a shows the block diagram of PD measurement setup. The PD measurement setup consisted of high voltage transformer, coupling capacitor, coupling quadripole, test object, Band pass filter and PD detector. The input supply to high voltage transformer is regulated by a special control unit which helps to achieve a constant voltage across the test object and other PD equipment. Coupling capacitor produces a current waveform proportional to the discharge voltages in the test object. Coupling quadripole converts the PD discharge current pulses produced by the coupling capacitor into a low voltage signal. This signal is then fed to band pass filter and PD detector. The final PD

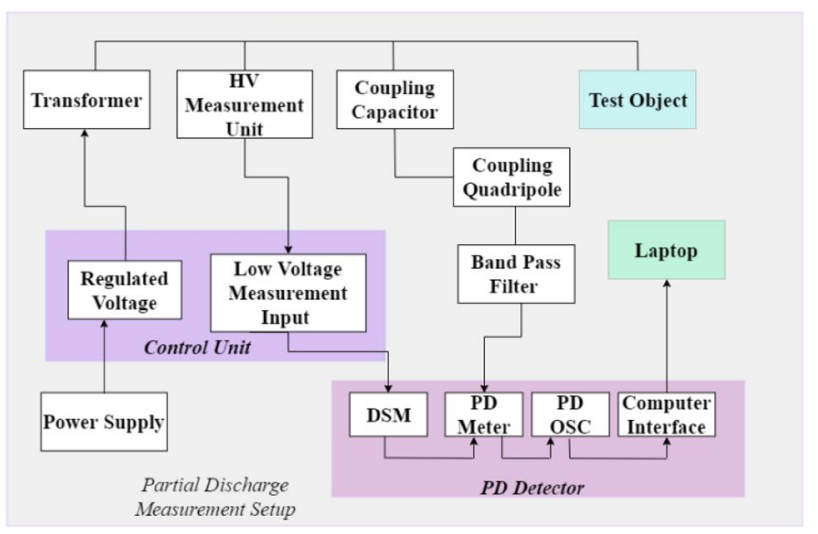

(a)

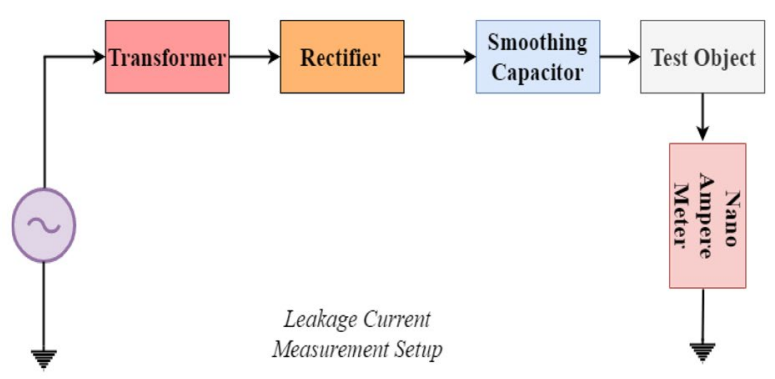

(b)

Fig. 1 Measurements setup (a) partial discharge (b) leakage current measurement setup

discharge waveform along with the other parameters are displayed and stored on the computer attached with PD detector by means of PD GOLD software. Figure $1 \mathrm{~b}$ shows the block diagram of LC measurement setup. In this setup a DC voltage is applied across the specimen and current was measured by a nano ampere meter connected in series with the specimen and ground electrode.

\section{Results and discussion}

\subsection{Leakage current}

The small amount of current which flows through the insulation even in healthy state is called LC [29]. In high
Table 2 Formulations of nano composites

\begin{tabular}{llllllll}
\hline Base matrix & Type of nano particle & \multicolumn{2}{l}{$\%$ Age of nano particle } \\
\cline { 3 - 8 } & & 0.30 & 0.40 & 0.50 & 0.60 & 0.70 & 0.80 \\
\hline Zepoxy 300 & $\mathrm{SiO}_{2}$ & $\mathrm{~S}_{1}$ & $\mathrm{~S}_{2}$ & $\mathrm{~S}_{3}$ & $\mathrm{~S}_{4}$ & $\mathrm{~S}_{5}$ & $\mathrm{~S}_{6}$ \\
& $\mathrm{TiO}_{2}$ & $\mathrm{~T}_{1}$ & $\mathrm{~T}_{2}$ & $\mathrm{~T}_{3}$ & $\mathrm{~T}_{4}$ & $\mathrm{~T}_{5}$ & $\mathrm{~T}_{6}$ \\
& $\mathrm{TiO}_{2} @ \mathrm{SiO}_{2}$ & $\mathrm{TS}_{1}$ & $\mathrm{TS}_{2}$ & $\mathrm{TS}_{3}$ & $\mathrm{TS}_{4}$ & $\mathrm{TS}_{5}$ & $\mathrm{TS}_{6}$ \\
\hline
\end{tabular}


voltage insulation systems $L C$ is an important factor as it is a direct indicator of many degradation phenomenon going on inside the insulation. The LC directly depends upon the surface and volume resistivity of insulation material. The less LC; better is the insulation. The total amount of LC flowing through an insulation material is contributed by three components. One component is surface resistivity which is a boundary of material with air. 2 nd component is the current flowing through the inner bulk of the material. 3rd component is contributed by any PD in the cavities formed within the material during its manufacturing or created afterwards due to the mechanical stresses. The first two components of current increase gradually with aging whereas the 3rd component may increase suddenly. So the total amount of $L C$ is rapidly increased if PD activity increases. However, every material has different mechanisms governing the increase in LC value with increasing PD activity.

$\mathrm{LC}$ of all the formulations mentioned above was measured at varying voltages and the result is shown in Fig. 2 . A linear relationship was observed between the LC and applied voltage for all the formulated nano composites. However, the relationship between the filler loading and $\mathrm{LC}$ is highly dependent upon the type of nano particle. This means that some nano particles increase the LC with increase in their percentage in the base matrix, while others do vice versa.

$\mathrm{SiO}_{2}$ nano particles have shown a decrease in the amount of LC with increasing their percentages in the base matrix. This is because $\mathrm{SiO}_{2}$ nano particles are highly non-conductive in nature. The effect of $\mathrm{SiO}_{2}$ nano particles on LC can be seen in the Fig. 2a. $0.3 \%$ filler loading of $\mathrm{SiO}_{2}$ particles in base matrix has shown highest LC compared to other percentages investigated. However, it does not necessarily mean that ever increasing the percentage of $\mathrm{SiO}_{2}$ particles in base matrix will always result in decrease of LC. There must be an upper threshold of percentage which can be used achieve better results. In these results $0.6 \%$ filler loading has minimum value of $\mathrm{LC}$. So, $0.6 \%$ can be regarded as optimum point in case of $\mathrm{SiO}_{2}$ zepoxy nano composites. It has been reported in [30] that resistivity of Nano composite formed with $\mathrm{SiO}_{2}$ starts to decrease once the percentage of $\mathrm{SiO}_{2}$ is increased beyond $1 \%$ in the base matrix.

In case of $\mathrm{TiO}_{2}$ nano particles amount of $\mathrm{LC}$ increases with the increase in filler concentration. Because $\mathrm{TiO}_{2}$ particles are a little bit conductive in nature as compared to $\mathrm{SiO}_{2}$, so increasing their concentration in base polymer decreases the dielectric strength of nano composite. It can be seen from the Fig. $2 \mathrm{~b}$ that $0.8 \%$ of $\mathrm{TiO}_{2}$ nano particles in the formulated nano composite gives highest value of $\mathrm{LC}$ at all applied voltages. The minimum value of $\mathrm{LC}$ occurs on $0.4 \%$ filler loading. This pattern of increasing LC with the

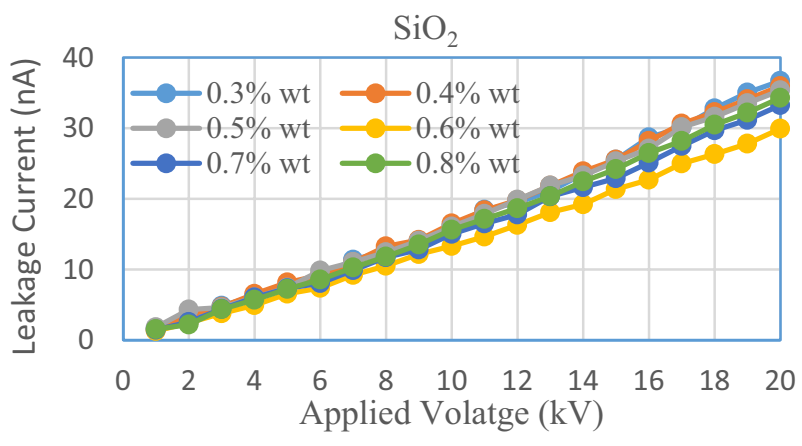

(a)

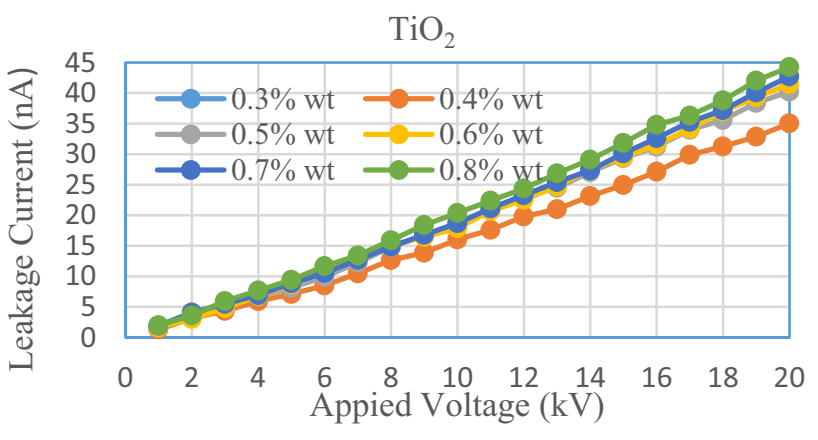

(b)

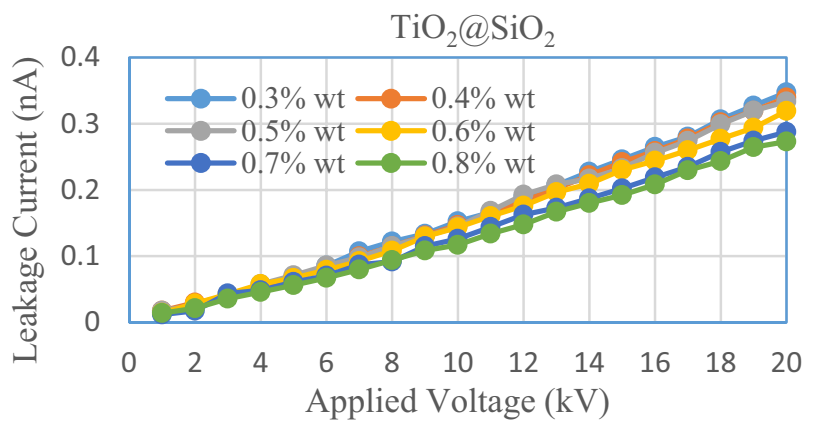

(c)

Fig. 2 Leakage current behavior zepoxy nano-composites a $\mathrm{SiO}_{2}$ based $\mathbf{b} \mathrm{TiO}_{2}$ based and $\mathbf{c} \mathrm{TiO}_{2} @ \mathrm{SiO}_{2}$ based zepoxy nano-composites

increase in $\mathrm{TiO}_{2}$ concentration has been also reported by Madusanka et al. [31].

In $\mathrm{TiO}_{2} @ \mathrm{SiO}_{2}$ nano composite the amount of LC decreases with the increase in nano filler concentrationas shown in Fig. 2c. There is distinct difference between values of $\mathrm{LC}$ at each concentration and no overlapping of values is observed in case of $\mathrm{TiO}_{2} @ \mathrm{SiO}_{2}$. Value of $\mathrm{LC}$ decreases with the increase in filler concentration. Volume resistivity and dielectric strength of $\mathrm{TiO}_{2} @ \mathrm{SiO}_{2}$ was tested on 0, 0.5, 2 and $4 \%$ filler loading [17]. Dielectric strength of these nano composites is maximum at $0.5 \%$ filler loading. The 
dielectric strength and resistivity values of $\mathrm{TiO}_{2} @ \mathrm{SiO}_{2}$ nano composites of $0.3,0.4,0.4,0.6,0.7$ and $0.8 \%$ filler concentration were discussed in [23]. At $0.8 \%$ filler loading $L C$ is minimum. $\mathrm{LC}$ of $\mathrm{TiO}_{2} @ \mathrm{SiO}_{2}$ nano composites is just $0.28 \mathrm{nA}$ at $0.8 \%$ filler loading [23]. In this research the $\mathrm{LC}$ of $\mathrm{TiO}_{2} @$ $\mathrm{SiO}_{2}$ nano composites is $0.27 \mathrm{nA}$. Morever comparing $\mathrm{LC}$ of $\mathrm{TiO}_{2} @ \mathrm{SiO}_{2}$ with $\mathrm{TiO}_{2}$ and $\mathrm{SiO}_{2}$ nano composite shows that encapsulated particles has lower values of LC at corresponding filler concentration. Due to higher polarization of $\mathrm{TiO}_{2}$ and excellent insulation attributes of $\mathrm{SiO}_{2}$ the combination nano particle $\mathrm{TiO}_{2} @ \mathrm{SiO}_{2}$ shows minimum LC.

\subsection{Volume resistivity}

Resistivity is the measure of opposition to flow of electrons offered by a material. The materials having higher values of resistivity are good for high voltage insulation purposes. Volume resistivity of a material is its surface resistivity time's length divided by area. Volume resistivity of many base materials can be enhanced by addition of different kinds of nano particles. Among different kind of nano particles $\mathrm{SiO}_{2}, \mathrm{TiO}_{2}$ and $\mathrm{TiO}_{2} @ \mathrm{SiO}_{2}$ have shown promising performance in previously reported research. The surface resisitivity of different nano composites formulated in this study was measured and then volume resistivity was calculated as shown in Fig. 3.

It is obvious from Fig. 3 that raw zepoxy has a volume resistivity values of the order of $10^{14} \Omega$-cm. In Fig. 3a it can be observed that addition of $(0.5-0.8) \mathrm{wt} \%$ of silica nano particles causes an improvement in resistivity values. Resistivity at $0.5 \mathrm{wt} \%$ is $2.9 \times 10^{14} \Omega-\mathrm{cm}$ this value reaches up to $3.4 \times 10^{14} \Omega-\mathrm{cm}$ when filler concentration is $0.6 \mathrm{wt} \%$.

In case of titania nano composite a decreasing trend of resistivity was observed with the increase in filler concentration. At $0.3 \%$ filler loading value is $2.6 \times 10^{14} \Omega-\mathrm{cm}$ this value is reduced to $2.3 \times 10^{14} \Omega-\mathrm{cm}$ at $0.8 \%$ concentration in Fig. 3b. Decrement in resistivity values is due to the slightly conductive nature of titania nano particles. When concentration of titania particles is increased in base polymer, inter and intra molecular forces become weak due to which the conductive effect dominates and resistivity decreases. At $0.4 \%$ filler loading resistivity is maximum in case of $\mathrm{TiO}_{2}$ nano composites.

ForTiO $\mathrm{TSiO}_{2}$ nano composite resistivity improved with the increase in filler concentration. Figure $3 \mathrm{c}$ shows that resistivity is $2.94 \times 10^{16} \Omega-\mathrm{cm}$ at $0.3 \%$ this value gradually increased to $3.23 \times 10^{16} \Omega-\mathrm{cm}$ at $0.6 \%$ concentration. At $0.7 \%$ resistivity is $3.52 \times 10^{16} \Omega-\mathrm{cm}$ and $3.81 \times 10^{16} \Omega$-cm at $0.8 \%$ loading which shows that resistivity value has increased $23 \%$ from $0.3 \%$ filler loading. The reason behind this is the formation of an electric double layer which is produced by the encapsulation of $\mathrm{TiO}_{2}$ in the sheath of $\mathrm{SiO}_{2}$. This double layer plays a

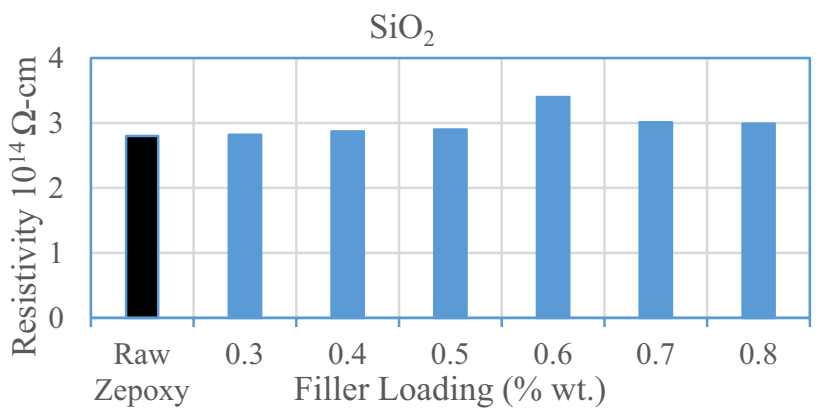

(a)

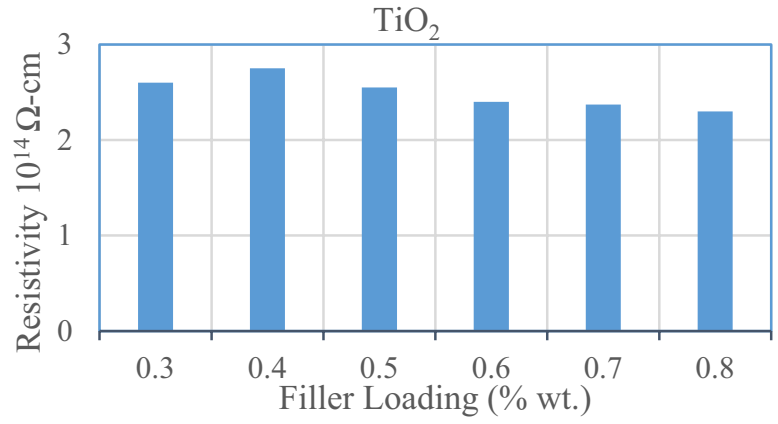

(b)

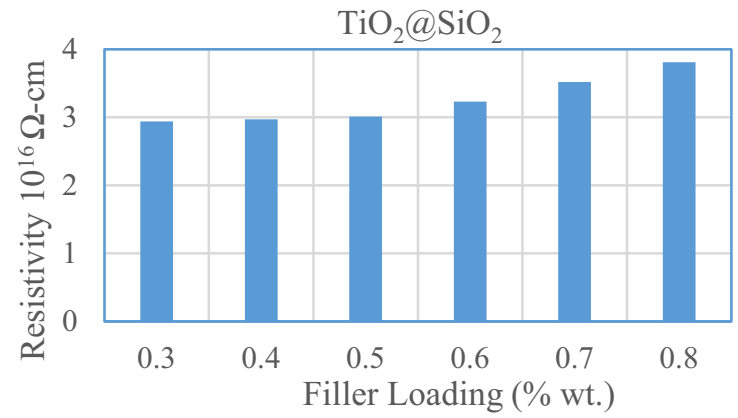

(c)

Fig. 3 Resistivity of zepoxy nano-composites a $\mathrm{SiO}_{2}$ based $\mathbf{b} \mathrm{TiO}_{2}$ based and $\mathbf{c} \mathrm{TiO}_{2} @ \mathrm{SiO}_{2}$ based zepoxy nano-composites

significant role on the dielectric properties of nano composites. The charges injected from the electrodes in nano composite materials are trapped by layers of the nano particles. When a certain amount of charges is absorbed by the nano particles present within a nano composite material, further injection of charges is stopped by repulsive forces. Formation of these repulsive forces effectively causes a kind of electrical barrier which has been termed as electric double layer by researchers in previous studies $[7,17,23,32]$. It has also been observed in previous researches that formation of electric double layer is the back bone of the dielectric strength of nano composites. 


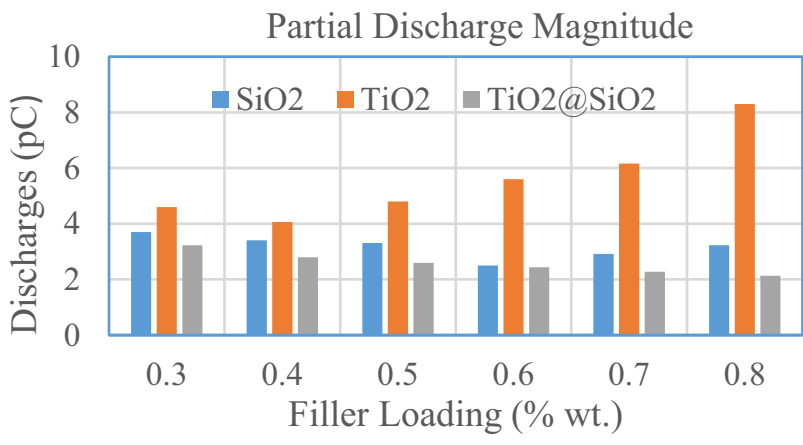

Fig. 4 Partial discharges of zepoxy nano-composites

\subsection{PD magnitude}

PD is a localized breakdown on a very small portion of insulation material. PD are undesirable in high voltage insulation materials because these discharges deteriorate the insulation materials chemically and physically. This degradation ultimately results in early insulation failure if discharges take place for a long period of time.

PD of insulation was measured according to IEC 60270 standard. The PD results are given in Fig. 4. From Fig. 4 it can be observed that $\mathrm{TiO}_{2} @ \mathrm{SiO}_{2}$ nano composites has least magnitude of $\mathrm{PD}$ as compared to $\mathrm{SiO}_{2}$ and $\mathrm{TiO}_{2}$ nano composites at all filler loadings. By comparing discharge results with LC it can be observed that for each type of nano composites minimum value of discharges and LC occur at the same filler loading.

\subsection{PD inception and extinction voltages}

To investigate the discharge behavior PDIV, PDEV and apparent value of PD in Pico coulombs are very important. PDIV and PDEV were measured according to IEC 60270 and 61294 standards [33, 34]. PDIV value depends upon the rate of rise of voltage and PDEV depends upon both the time and decay rate of voltage. PDIV and PDEV were measured by varying voltages up to $20 \mathrm{kV}$. PDIV and PDEV of prepared nano composites are given in Fig. 5 .

It was observed that at each filler loading of different nano particles PDIV is higher than PDEV. Figure 5a shows the variation of PDIV and PDEV for various filler loading of $\mathrm{SiO}_{2}$ nano particles. A decreasing trend in PDIV and PDEV values was observed when filler loading is increased up to $0.5 \%$. These values again increase when filler loading is 0.6 and $0.7 \%$. Minimum values of PDIV and PDEV occur at $0.5 \%$ loading while their maximum values occur at $0.6 \%$ loading. Figure $5 \mathrm{~b}$ shows the PDIV and PDEV of $\mathrm{TiO}_{2}$ nano composites. From results it is clear that minimum values of PDIV and PDEV occur at $0.6 \%$ filler loading. At $0.4 \%$ filler loading PDIV and PDEV values are maximum. Figure $5 \mathrm{C}$

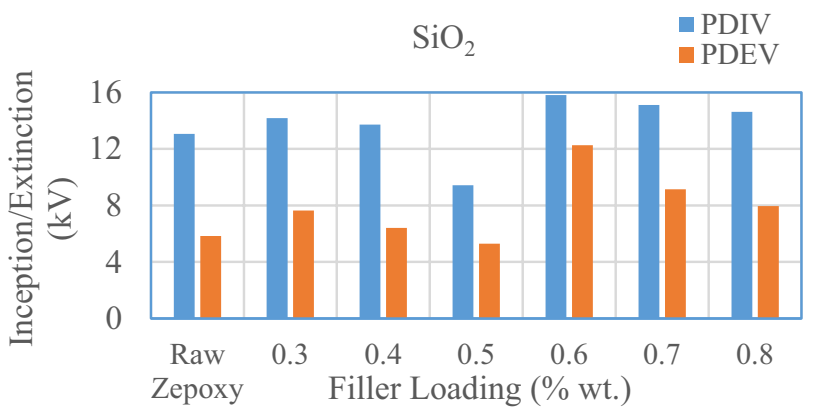

(a)

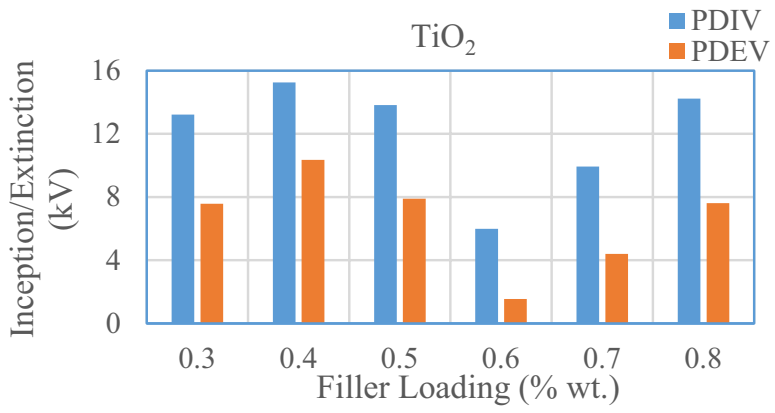

(b)

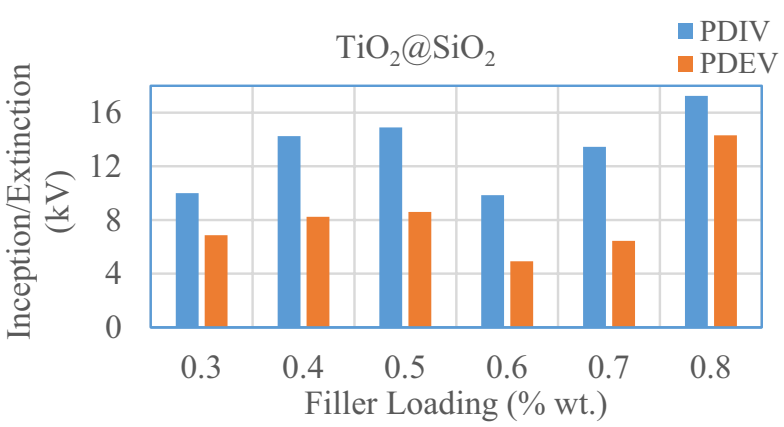

(c)

Fig. 5 Partial discharge inception/extinction behavior of zepoxy nano-composites $\mathbf{a} \mathrm{SiO}_{2}$ based $\mathbf{b} \mathrm{TiO}_{2}$ based and $\mathbf{c} \mathrm{TiO}_{2} @ \mathrm{SiO}_{2}$ based zepoxy nano-composites

shows the trend in the values of PDIV and PDEV for $\mathrm{TiO}_{2} @$ $\mathrm{SiO}_{2}$ nano composites. It was observed that minimum values occur at $0.6 \%$ filler loading, however maximum values occur at $0.8 \%$ filler loading. It can also be observed that for each type of nano particles the maximum values of PDIV and PDEV occur for the $\mathrm{TiO}_{2} @ \mathrm{SiO}_{2}$ nano particles. From which it can be concluded that $\mathrm{TiO}_{2} @ \mathrm{SiO}_{2}$ nano composites give better resistance against $\mathrm{PD}$ as compared to that of $\mathrm{TiO}_{2}$ and $\mathrm{SiO}_{2}$ nano composites. The reason behind is the chemistry of $\mathrm{TiO}_{2} @ \mathrm{SiO}_{2}$ nano particles, which is based on two different oxides; $\mathrm{SiO}_{2}$ having excellent insulation properties and $\mathrm{TiO}_{2}$ having a slightly conductive nature. This results in better insulation and uniform space charge 


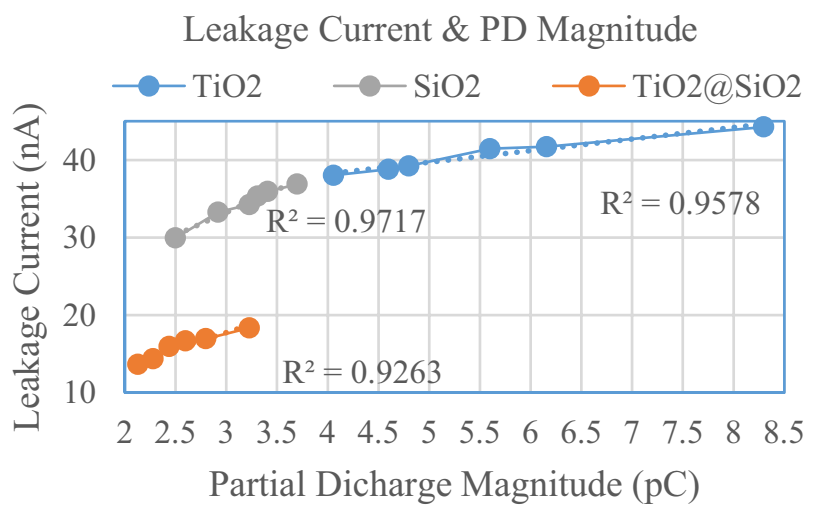

Fig. 6 Dependence of leakage current on PD

distribution of the formulated nano composites which in turn results in low value of $L C$ and PD. As reported in literature $[30,35,36]$ and also found in this study both the $\mathrm{SiO}_{2}$ and $\mathrm{TiO}_{2}$ have higher values of $\mathrm{LC}$ and $\mathrm{PD}$ as compared to $\mathrm{TiO}_{2} @ \mathrm{SiO}_{2}$.

\subsection{Dependence of LC on PD magnitude}

The relationship between LC and PD is plotted by taking values at $20 \mathrm{kV}$ for all samples. The result is shown in Fig. 6. The actual values of $\mathrm{LC}$ for $\mathrm{TiO}_{2} @ \mathrm{SiO}_{2}$ nano composite are multiplied by a factor of 50 to make it observable on graph scale. Linear curve fitting is applied to all three formulations and $R$ squared values are shown in Fig. 6 . In all cases $R^{2}$ values are higher than 0.95 , so it can be concluded that increase in the PD magnitude linearly increases the magnitude of $L C$. Since measurement of PD is a complex procedure to deploy in field measurements, so LC measurement could be an excellent screening tool to find whether the PD is within allowable limits or not. However, to use this method for health assessment of any insulation in field it should be first investigated in lab to find the threshold values of LC and PD for a new insulation material under consideration, so as to calibrate the results from the field obtained afterwards.

\section{Conclusion}

Highest values of LC and PD were observed at filler loading of $0.3 \%$ for $\mathrm{SiO}_{2}$ (35.94 nA, $3.7 \mathrm{pC}$ ), $0.8 \%$ for $\mathrm{TiO}_{2}(44.27$ $\mathrm{nA}, 8.3 \mathrm{pC})$ and around 0.3-0.4\% for $\mathrm{TiO}_{2} @ \mathrm{SiO}_{2}(0.33 \mathrm{nA}$, $3 \mathrm{pC}$ ). Lowest values of $\mathrm{LC}$ and $\mathrm{PD}$ were observed at filler loading of $0.6 \%$ for $\mathrm{SiO}_{2}(29.94 \mathrm{nA}, 2.5 \mathrm{pC}), 0.4 \%$ for $\mathrm{TiO}_{2}$ (35.03 nA, $4.06 \mathrm{pC}$ ) and 0.8\% for $\mathrm{TiO}_{2} @ \mathrm{SiO}_{2}$ (0.27 nA, 2.13 $\mathrm{pC})$. It can be concluded that every nano particle has different effect on the properties of base materials. Also every nano particle has a different optimum percentage where it shows the maximum improvement in properties of base material. Both $\mathrm{SiO}_{2}$ and $\mathrm{TiO}_{2} @ \mathrm{SiO}_{2}$ nano particles have shown improvement in properties of base material with increasing percentage whereas $\mathrm{TiO}_{2}$ particles have opposite behavior. It can be explicitly concluded that the optimal filler loadings of $\mathrm{SiO}_{2}, \mathrm{TiO}_{2}$ and $\mathrm{TiO}_{2} @ \mathrm{SiO}_{2}$ are 0.6, 0.4 and $0.8 \%$ respectively. These optimal filler loadings have minimum values of $L C$ and PD for best performance of insulation.

In general, among all three nano composites investigated $\mathrm{TiO}_{2} @ \mathrm{SiO}_{2}$ nano composites demonstrated the best performance. In addition to that it has been seen that a very strong direct relationship exists between the $L C$ and PD magnitude. The observed values of $L C$ and PD at different percentages of nano particles vary widely but in all cases $\mathrm{LC}$ and PD are directly related with each other when compared at a specific percentage. Ease of measurement of $L C$ as compared to PD could be of great practical value in online insulation health monitoring.

Author's contribution Additionally, all the named authors have contributed equally.

\section{Compliance with ethical standards}

Conflict of interest The authors that they no conflict of interest.

\section{References}

1. Iyer G, Gorur RS, Richert R et al (2011) Dielectric properties of epoxy based nanocomposites for high voltage insulation. IEEE Trans Dielectr Electr Insul 18:659-666

2. Singh V, Kulkarni AR, Mohan TRR (2003) Dielectric properties of aluminum - epoxy composites. J Appl Polym Sci 90:3602-3608

3. Fothergill JC, Nelson JK, Fu M (2004) Dielectric properties of epoxy nanocomposites containing $\mathrm{TiO}_{2}, \mathrm{Al}_{2} \mathrm{O}_{3}$ and $\mathrm{ZnO}$ fillers. In: The 17th annual meeting of the IEEE lasers and electro-optics society, pp 406-409

4. Nelson JK, Fothergill JC, Dissado LA, Peasgood W (2003) Towards an understanding of nanometric dielectrics. In: Annual report conference on electrical insulation and dielectric phenomena, pp 295-298

5. Roy M, Nelson JK, Maccrone RK et al (2005) Polymer nanocomposite dielectrics - the role of the interface. IEEE Trans Dielectr Electr Insul 12:629-643

6. Tanaka T (2005) Dielectric nanocomposites with insulating properties. IEEE Trans Dielectr Electr Insul 12:914-928

7. Tanaka T, Kozako M (2005) Proposal of a multi-core model for polymer nanocomposite dielectrics. IEEE Trans Dielectr Electr Insul 12:669-681

8. Nelson JK (2004) Fothergill JC internal charge behaviour of nanocomposites. Nanotechnology 15:1-28

9. Singha S, Thomas MJ (2008) Dielectric properties of epoxy nanocomposites. IEEE Trans Dielectr Electr Insul 15:12-23

10. Tanaka T, Nose A et al (2006) PD resistance evaluation of LDPE/ $\mathrm{MgO}$ nanocomposite by a rod-to-plane electrode system. In: 
IEEE 8th international conference on properties \& applications of dielectric materials, pp 319-322

11. Fukuoka K, Kagoshima A (2005) Insulation properties of nanoand micro-filler mixture composite. In: CEIDP'05. 2005 annual report conference on electrical insulation and dielectric phenomena, 2005. pp 171-174

12. Tanaka T (2008) Enhanced partial discharge resistance of epoxy/ clay nanocomposite prepared by newly developed organic modification and solubilization methods. IEEE Trans Dielectr Electr Insul 15:81-89

13. Lee C, Park J (2010) The partial discharge resistances of epoxynano-and- micro composites. Trans Electr Electron Mater 11:89-91

14. Preetha P, Thomas MJ (2011) Partial discharge resistant characteristics of epoxy nanocomposites. IEEE Trans Dielectr Electr Insul 18:264-274

15. Li Z (2011) The role of nano and micro particles on partial discharge and breakdown strength in epoxy composites. IEEE Trans Dielectr Electr Insul 18:675-681

16. Li Z (2010) Effects of nano-filler addition on partial discharge resistance and dielectric breakdown strength. IEEE Trans Dielectr Electr Insul 17:653-661

17. Chen Y, Wu J (2016) Investigation on relationship between breakdown strength enhancement of composites and dielectric characteristics of nanoparticle. IEEE Trans Dielectr Electr Insul 23:927-934

18. Siddabattuni S, Akella SH, Gangula A et al (2018) Dielectric properties study of surface engineered nano TiO2/epoxy composites. Bull Mater Sci 41:1-9

19. Kim P, Jones SC, Hotchkiss PJ et al (2007) Phosphonic acidmodified barium titanate polymer nanocomposites with high permittivity and dielectric strength. Adv Mater 19:1001-1005

20. Schuman TP, Siddabattuni S, Cox O, Dogan F (2010) Improved dielectric breakdown strength of covalently-bonded interface polymer-particle nanocomposites. Compos Interfaces 17:719-731

21. Wang Z, Liu J, Cheng Y et al (2018) Alignment of boron nitride nanofibers in epoxy composite films for thermal conductivity and dielectric breakdown strength improvement. Nanomater $8: 1-14$

22. Wang Z, Cheng $Y$, Yang $M$ et al (2018) Dielectric properties and thermal conductivity of epoxy composites using core/ shell structured Si/SiO2/Polydopamine. Compos Part B Eng 140:83-90

23. Awais M (2019) Investigation on optimal filler loadings for dielectric strength enhancement of epoxyTiO2@SiO2 nanocomposite. Mater Res Express 6:0-8

24. Mboungou E, Mavon C, Friedt JM et al (2008) Impact of water content on the electrical behavior of epoxy insulators. IEEE Trans Dielectr Electr Insul 15:311-318
25. Sakoda T, Tabira K, Miyake T et al (2018) Discharge behavior and dielectric performance of artificially polluted hydrophobic silicone rubber. J Electrostat 93:97-103

26. Isaka K, Yokoi Y, Naito K, Matsuoka R et al (1990) Development of real-time system for simultaneous observation of visual discharges and leakage current on contaminated dc insulators. IEEE Trans Electr Insul 25:1153-1160

27. Paoletti G, Golubev A (2006) Partial discharge theory and applications to electrical systems. In: Conference record of 1999 annual pulp and paper industry technical conference (Cat. No. 99CH36338), pp 124-138

28. Dutta K (2007) Electrical conductivity and dielectric properties of $\mathrm{SiO}_{2}$ nanoparticles dispersed in conducting polymer matrix. J Nanoparticle Res 9:631-638

29. Amin M, Amin S, Ali M (2009) Monitoring of leakage current for composite insulators and electrical devices. Rev Adv Mater Sci 21:75-89

30. Abdelkarim MF, Elkhodary SM (2015) Volume resistivity and mechanical behavior of epoxy nanocomposite materials. Eng Technol Appl Sci Res 5:775-780

31. Madusanka N, Shivareddy SG, Hiralal P et al (2016) Nanocomposites of TiO2/cyanoethylated cellulose with ultra high dielectric constants. Nanotechnology 27:1-20

32. Lewis TJ (2004) Interfaces are the dominant feature of dielectrics at the nanometric level. IEEE Trans Dielectr Electr Insul $11: 739-753$

33. Turba T (2018) Measurement and diagnosis of Partial Discharges in low voltage applications. Publishing House of the Opole University of Technology, pp 117-120

34. Pattanadech N, Pratomosiwi F, Wieser B, et al (2012) The study of partial discharge inception voltage of mineral oil using needle-plane electrode configuration. In: International conference on high voltage engineering and application, $\mathrm{pp} 2-5$

35. Othman NA, Piah MAM, Adzis Z, Al-Geelani NA (2016) Partial discharge characterization based on leakage current pulses waveform for contaminated glass insulator string. Int J Electr Comput Eng 6:835-843

36. Slama MEA, Beroual A (2015) Behavior of ac high voltage polyamide insulators: evolution of leakage current in different surface conditions. Adv Electr Electron Eng 13:74-80

Publisher's Note Springer Nature remains neutral with regard to jurisdictional claims in published maps and institutional affiliations. 